\title{
Analysis of the Cellular Infiltration of Benzyl-Esterified Hyaluronan Sponges Implanted in Rats
}

\author{
Nicholas P. Rhodes, ${ }^{, \dagger}$ Chiara Di Bartolo, ${ }^{\ddagger}$ and John A. Hunt ${ }^{\dagger}$ \\ U.K. Centre for Tissue Engineering, Department of Clinical Engineering, University of Liverpool, \\ Daulby Street, Liverpool L69 3GA, U.K., and Fidia Advanced Biopolymers, via Ponte della Fabbrica 3/A, \\ 35031 Abano Terme, Padova, Italy
}

Received April 3, 2007; Revised Manuscript Received June 14, 2007

\begin{abstract}
Unseeded sponges of benzyl-esterified hyaluronan (HYAFF11) and HYAFF11 coated with unmodified hyaluronan were implanted subcutaneously and intramuscularly in adult rats for 1, 2, 4, 8, 12, and 26 weeks. Explanted samples were stained tincturally using Van Geison, von Kossa, and hematoxylin and eosin, enzyme histochemically by chloroacetate esterase, and by immunohistochemistry for the specific identification of cell types and subpopulations, targeting immature (ED1) and mature macrophages (ED2), MHC-I subset, MHC-II subset, CD54, T-cell $\alpha-\beta$ receptor, T-cell $\gamma-\delta$ receptor, CD2, CD4, CD8, natural killer cells, B-cells, vimentin, and TGF $\beta$. Little or no fibrous tissue formation was observed in any sample in either sponge type at any implantation site. Little degradation was observed in either location until 26 weeks. Little neovascularization occurred at early time periods but was in evidence at 26 weeks. Complete cellular infiltration was observed after 4 weeks, with some mature adipocytes observed within the center of the subcutaneous implants, but these cells were mainly observed around the periphery of the sponges. At 26 weeks, cells were mostly macrophages, with small numbers of T-lymphocytes present. No natural killer cells, B-cells, helper/inducer, or cytotoxic/suppressor T-cells were observed in any sample. Most infiltrating cells were MHC-II positive, and discrete pockets of TGF $\beta$ protein were observed within the sponges. While a sustained inflammatory response was observed within both sponge types at 26 weeks, it was relatively benign and nonspecific immunologically, and inflammatory markers such as MHC-II were declining after 12 weeks. No fibrous capsule was observed, and sponge degradation was only observed at 26 weeks, an event essential for induction of neovasculargenesis. At 26 weeks, there was significant staining for vimentin and ED2 on macrophages. Taken with the pattern of other macrophage activation markers, angiogenic environment and absence of inhibitory matrix proteins, the conditions were consistent with the onset of neoadipogenesis, although this would need to be confirmed by longer term studies. For the generation of neoadipose tissue for clinical therapy, we hypothesize that macrophages require an inflammatory stimulus for infiltration, then a reduction in proinflammatory cytokine secretion simultaneous with angiogenic conditions allowing macrophage differentiation into adipocytes.
\end{abstract}

\section{Introduction}

Soft tissue deficiency is a clinically significant morbidity and is characteristic of hereditary disorders such as Poland syndrome $^{1}$ and Romberg's disease, ${ }^{2}$ in addition to mechanical trauma and the results of treatment for tumors (e.g., mastectomy). Current treatment paradigms have changed little over the past decades and have a number of significant clinical problems associated with them. These have been extensively reviewed previously. ${ }^{3,4} \mathrm{~A}$ surgical strategy which instead induces regeneration based on cellular tissue engineering principles may provide a practical solution. ${ }^{3,5-8}$ Another convincing route would be the implantation of an acellular biomaterial that would both support the growth of adipocytes and actively induce neovascularization of the graft. A plausible candidate for this application is hyaluronic acid due to its angiogenic properties ${ }^{9}$ and its role in tissue morphogenesis. ${ }^{10-12}$ Naturally occurring hyaluronan cannot be constructed into a tissue scaffold having the required mechanical properties, however, as it exists within natural tissue as a viscous fluid with high rates of hydrolytic degradation and resorption.

* Author to whom correspondence should be addressed.

†niversity of Liverpool.

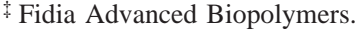

The solubility of hyaluronan can be dramatically reduced such that it is solid even after extended periods in aqueous environments by benzyl esterification of the free carboxyl groups on the glucuronic acid component of the hyaluronan chain (HYAFF) ${ }^{13}$ Furthermore, by varying the degree of carboxyl modification, the degradation rate can be tailored to meet the requirements of the implantation site and clinical application. ${ }^{14}$ It has been demonstrated in many studies that such chemical modification results in nontoxic degradation products, ${ }^{15,16}$ including free hyaluronan, which is highly angiogenic. ${ }^{9}$ A wide range of HYAFF-based biomaterials forms have been constructed, such as nonwoven fleeces, membranes, sponges, cylinders, and tubes and have been demonstrated as having efficacy when used as scaffolds in the reconstruction of skin, ${ }^{17,18}$ cartilage, ${ }^{19,20}$ bone, , 21,22 ligament, ${ }^{23,24}$ intervertebral disc, ${ }^{25}$ nerve guides, ${ }^{26}$ small-diameter vascular substitutes, ${ }^{27,28}$ and hepatic tissue. ${ }^{29}$ Moreover, it has been demonstrated that HYAFF-based sponges can support the differentiation of human adipocyte precursor cells in vitro ${ }^{30}$ and in vivo when implanted subcutaneously in nude mice. ${ }^{31,32}$ Conversely, synthetic polymers such as $\mathrm{PLGA}^{33}$ and $\mathrm{PTFE}^{34}$ have demonstrated severe limitations in soft tissue engineering applications, especially regarding the mechanical properties of the scaffolds. 


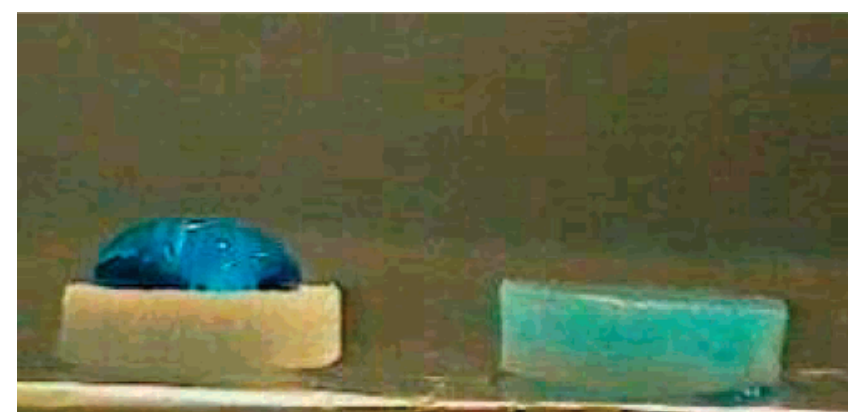

Figure 1. HYAFF11 (left) and HYAFF11 autoloading (right) sponges, demonstrating the effect of hydrophilic HA coating of HYAFF11.

We hypothesized, therefore, that a scaffold that supported the growth of differentiating precursor cells in an angiogenic environment would be a good strategy for soft tissue reconstruction. Thus, we have designed sponges constructed from HYAFF11 with both low and high hydrophobicity and with large pores that have demonstrated successful culture and differentiation of preadipocytes into mature adipocytes. ${ }^{30} \mathrm{We}$ hypothesize that these designs will result in the early neovascularization of the scaffolds and induce the infiltration of precursor cells that will lead to adipose formation.

In this study, we have investigated the ability of sponges constructed from HYAFF11, in unseeded form, to integrate successfully into subcutaneous and intramuscular tissue in vivo in rats. We report the detailed inflammatory response, the propensity for fibrotic capsule formation, and the phenotypic expression of infiltrating cells. The aim of this study is to investigate if hyaluronan-based scaffolds, such as HYAFF11, could be used to direct the infiltration of progenitor cells and drive differentiation into an adipogenic lineage without the prior inoculation with preadipocytes.

\section{Materials and Methods}

2.1. Materials. Sponges of hyaluronan which had been modified by partial benzyl esterification of the carboxyl groups (HYAFF11 p75HE) were prepared by Fidia Advanced Biopolymers (Abano Terme, Italy). These were cut into discs $14 \mathrm{~mm}$ in diameter, $4 \mathrm{~mm}$ high, constructed by salt leaching, with interconnecting porosity in the range of $350-400 \mu \mathrm{m}$. A second variety of sponge with improved hydrophilicity was also prepared by coating HYAFF11 p75HE sponge with unmodified hyaluronan and was termed autoloading (Figure 1). All samples were sterilized by $\gamma$-radiation.

2.2. Implantation. Sponges were immersed in DMEM tissue culture medium (Invitrogen, Paisley, U.K.) and degassed for $3 \mathrm{~h}$ under vacuum to disperse any air nuclei. The sponges were cut into four equal pieces, then implanted intramuscularly into the dorso-lumbar muscle of Wistar rats on both sides, after the surgical creation of a pocket. Additional pieces which were either whole or whole with a quarter segment removed (to allow differentiation between sponge types) were implanted subcutaneously in the dorso-lumbar region, either side of the spine. Both materials were implanted contralaterally in each configuration in each of 5 rats to allow comparison. Implantation time was 1, 2, 4, 8, 12, and 26 weeks. Approval for performing implantation surgery was given the by U.K. Home Office.

2.3. Characterization of the Host Response. Immediately after the sacrifice of experimental animals, both subcutaneous and intramuscular samples were explanted with the associated tissue. The sponges were fixed in paraformaldehyde lysine phosphate buffer (PLP fixative) and embedded in glycol methacrylate (GMA resin). They were then sectioned to $2-5 \mu \mathrm{m}$ and analyzed using the following conventional histological stains: Van Geison, von Kossa, chloroacetate esterase, and hematoxylin and eosin. Additional slides were also incubated with the following mouse primary antirat monoclonal antibodies: ED1 (monocytes and immature macrophages), ED2 (differentiating macrophages), MHC-I (HLA RT1A subset), MHC-II (HLA DLR subset), CD54 (ICAM-1), $\alpha-\beta$ receptor (T-cell subset), $\gamma-\delta$ receptor (T-cell subset), CD2 (normal T-cells), CD4 (helper/inducer T-cells), CD8 (cytotoxic/ suppressor T-cells), CD161 (natural killer cells), B-cells, vimentin, and TGF $\beta$, which were all obtained from Serotec (Oxford, U.K.). These were reacted with biotinylated rabbit antimouse immunoglobulin (DakoCytomation, Cambridge, U.K.), and the color was developed with alkaline phosphatase. PBS was used as the process negative control, and the panel of antibodies was run together on two samples per full staining protocol to act as internal reference and isotype controls for the staining procedure. Numbers of cells and their activation state were calculated using an Image Associates KS400 image analysis system (Cambridge, U.K.). Statistical significance was determined by ANOVA, utilizing Tukey post hoc analysis with significance determined at the 95\% confidence level using SPSS version 10 (Chicago, IL).

\section{Results}

The HYAFF sponges produced a margin of neutrophil sequestration in both subcutaneous and intramuscular implantation sites after 1 week that was both around and inside the margins of the sponges, but otherwise the samples were not infiltrated by cells. All internal spaces of the sponges, of both varieties, however, were characterized by complete cellular infiltration by 4 weeks. The apparent characteristics of the cellular infiltration were largely unchanged during all subsequent time periods, post 4 weeks, in both sponge varieties and in both anatomical implantation sites. Mature adipocytes from the subdermal layer were frequently observed at the margins of the sponges at the 8 week and later implantation periods (Figure 2 ) in subcutaneous implants, with individual cells and small clusters occasionally observed within the center of the sponge. Fibrous tissue was either not observed or present as a thin layer around the periphery of the implants at each time period in both implantation sites. In the latter case, this tissue did not represent a fibrous capsule in macroscopic examination.

No sponge degradation could be detected until the 26 week implantation period in both subcutaneous and intramuscular sites (Figure 3). There was evidence of neovascularization (Figure 4), particularly in the 26 week explants, although the number of blood vessels observed at early time periods was limited.

There was no evidence of the recruitment of B-lymphocytes, and infiltrating cells were predominantly positively identified as mature and immature macrophages $(\sim 90 \%)$, with a small number of infiltrating T-lymphocytes (Figures 5 and 6), as determined by the expression of CD2. Absence of staining for both CD4 and CD8 indicated that no lymphocytes were of the helper/inducer or cytotoxic/suppressor subpopulations, respectively. Negative staining for CD161 indicated that no natural killer cells were present in any sample. Discrete pockets of $\operatorname{TGF} \beta$ were visible throughout the sponges. Many of the cells present within the scaffolds, in both sites, were MHC-II positive, especially at the earlier time points, although positive staining had declined by 26 weeks.

At 26 weeks, the expression profile of vimentin matched closely with the presence of ED2 positive (differentiating) macrophages in the subcutaneous implants and was expressed on approximately one-fifth of the total macrophage population in intramuscular sites.

There was no apparent difference in the host response between HYAFF11 and HYAFF11 autoloading in any of the explanted samples. In addition, there was broad agreement in 


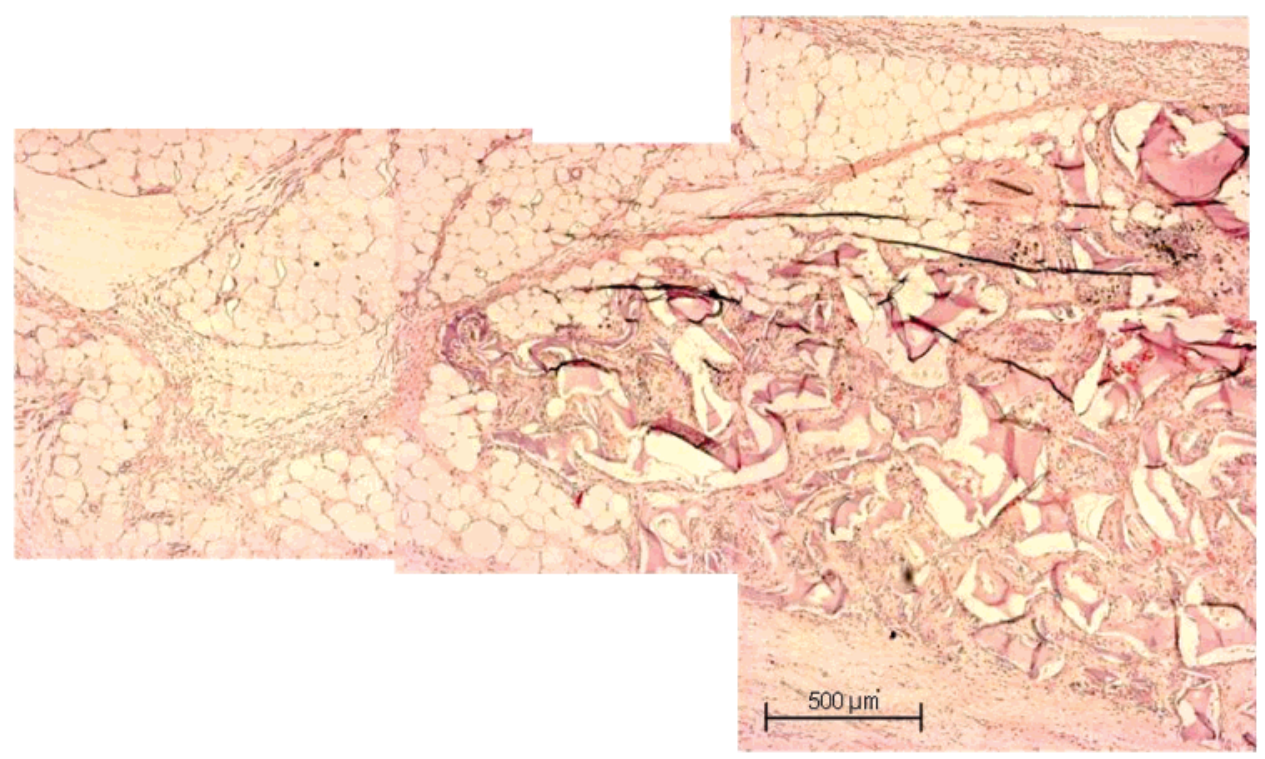

Figure 2. HYAFF11 autoloading, 12 weeks subcutaneous implantation, hematoxylin and eosin stained.

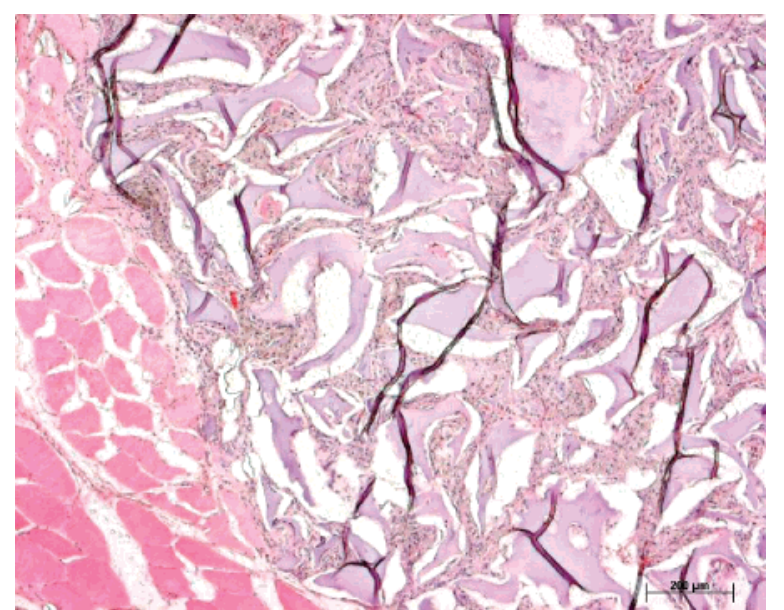

Figure 3. HYAFF11 autoloading, 26 weeks intramuscular implantation, hematoxylin and eosin stained.

the qualitative and quantitative observations between subcutaneous and intramuscular implantation sites.

\section{Discussion}

Adipose tissue has only recently been understood to have a vital role in host defense and an active function in cytokine signaling and secretion..$^{35-37}$ Thus, it should come as no surprise that clinical or experimental regeneration of adipose tissue is critically dependent on the trophic microenvironment to which precursor cells are exposed. Together with the effect of the scaffold surface chemistry on implanted and infiltrating cells and biomechanical signaling, biochemical cues are responsible for directing correct tissue development. It has become apparent that many studies report the level of inflammation by mere qualitative assessment of the density of infiltrating cells and completely fail to take into account the detailed nature of the inflammatory cell activation and other parameters of the host response. Thus, we believe that by investigating the activation status of the infiltrating lymphocytes and macrophages, a more clear understanding of the ability of different scaffolds to present an appropriate environment for the development of adipose tissue will emerge. We report here our experience of the results of the host response in vivo to HYAFF11 sponges implanted both intramuscularly and subcutaneously in rats and detail the effect of infiltrating inflammatory cells.

Many previous studies have described reduced adipocyte differentiation in inflammatory milieu. ${ }^{38,39}$ On the contrary, inflammatory chemokines induce the infiltration of both preadipocytes and circulating cells which have the capacity to differentiate into adipocytes. ${ }^{40,41}$ Additionally, the close association between angiogenesis and adipogenesis is well recognized, ${ }^{42}$ angiogenesis being profoundly augmented by inflammatory conditions. Recent observations have concluded that transdifferentiation between adipocytes or preadipocytes and macrophages occurs, ${ }^{35,43}$ suggesting a role for white adipose tissue in the host inflammatory response. Furthermore, the emerging opinion is that obesity can be considered in part a chronic manifestation of low-grade inflammation. ${ }^{44-46}$ Additionally, adipocyte-endothelial cell interconversion has been reported $^{36,47}$ suggesting a common precursor cell for adipocytes and endothelial cells which would explain the close association between angiogenesis and adipogenesis. ${ }^{42}$ Finally, a consistent picture begins to emerge when one considers that circulating endothelial progenitor cells, generally regarded as the precursor for new endothelium, derives from a monocyte, ${ }^{48,49}$ the precursor of the macrophage.

In this study, integration with the host tissue was observed in both implant sites for both sponge types. In the correction of cosmetic defects the presence of a thick fibrous capsule would be particularly inappropriate. Both varieties of the HYAFF11 sponges analyzed in this study performed well in this respect. The results demonstrate that HYAFF11 is, in long-term implantation, compatible with the presence of mature adipocytes. These were observed at the margins and, infrequently, deep within the sponges in subcutaneous sites. This suggests that, although there is unlikely to be any severe inhibition to growth of this cell type, infiltration is being restricted. This is unlikely to be for physical or dimensional reasons, as macrophages and T-lymphocytes were freely mobile within the sponges. Conversely, the profile of vimentin expression has been linked to the start of differentiation of macrophages into adipocytes, ${ }^{50}$ but cells were only positively stained for vimentin at 26 weeks. Consistent with this observation is the delayed onset of sponge degradation, which, unusually for HYAFF, showed no sign of resorption until after 12 weeks. The degradation profile of the sponges is likely to drive vascularogenesis, due to the release 
(a)

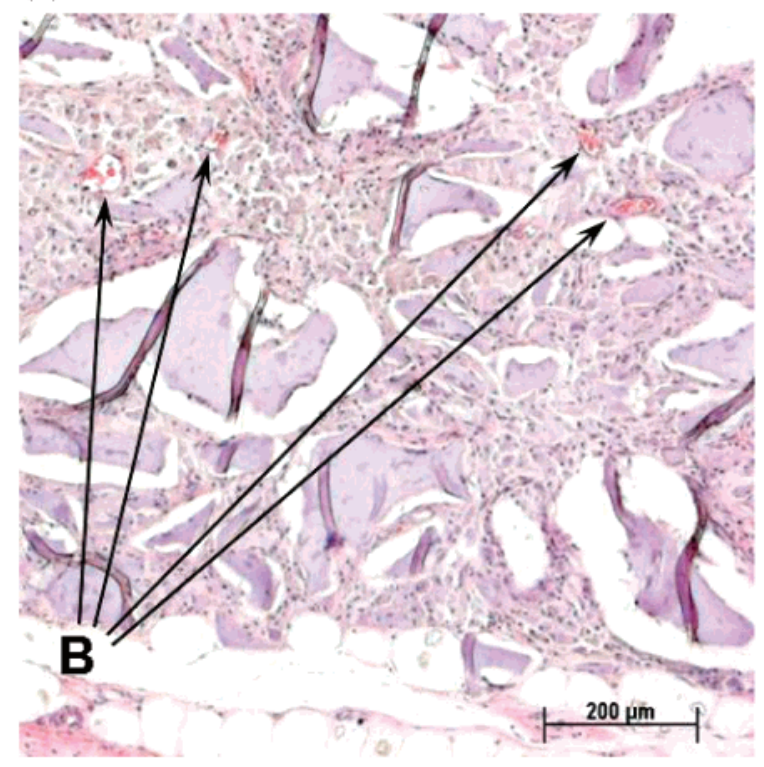

(b)

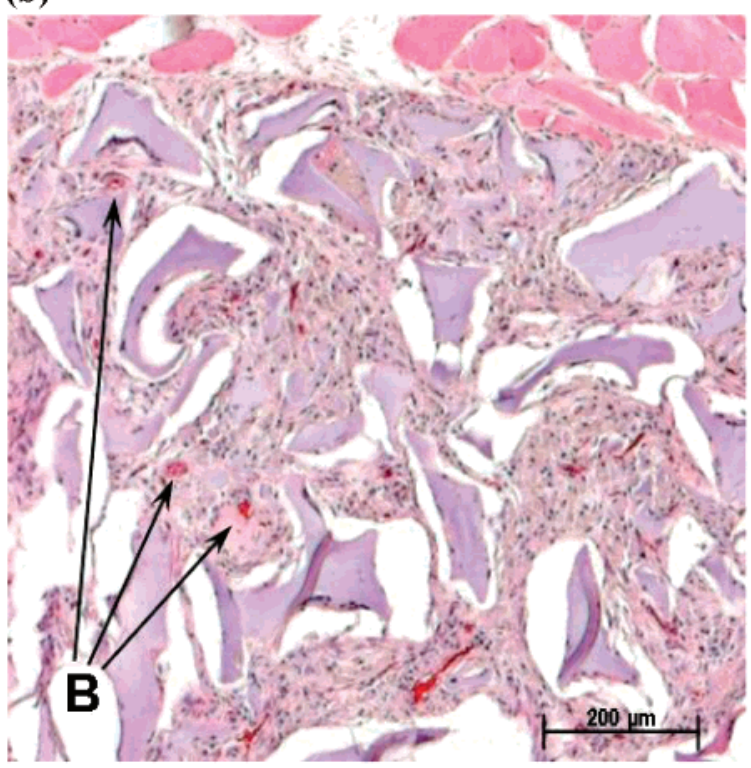

Figure 4. HYAFF11 autoloading sponges, 26 weeks implantation in the rat, hematoxylin and eosin stained, indicating the presence of neovessels, labeled "B": (a) subcutaneous; (b) intramuscular.

of free hyaluronan monomers, so the observation that blood vessels within the sponge were rarely found at early time periods, but more frequently at 26 weeks, would be expected.

Macrophage infiltration into implanted scaffolds occurs as a direct result of the secretion of proinflammatory chemokines, such as IL- $1 \beta$, MCP-1, and TGF $\beta$, secreted in part due to the implantation surgery. If sustained macrophage recruitment persists within an implanted scaffold, phagocytosis of the biomaterial will ultimately result in its complete destruction. Measurement of the activation state of these macrophages provides an indication of the presence of a chronic inflammatory response. The observation of the presence of macrophages over a 26 week period would normally lead to the conclusion that the scaffold was proinflammatory and likely to lead to clinical failure. In the case of HYAFF11 reported here, the presence of an inflammatory response was clear, as indicated by the high expression of MHC-II at time periods up to 12 weeks, but decreased significantly thereafter.
In the case of regenerating adipose tissue, we wish to cause the infiltration of macrophages, then allow them to spontaneously differentiate into adipocytes. Spontaneously differentiation is observed in vitro when expansion is arrested and fetal calf serum is present in the medium, ${ }^{51}$ with or without cell confluence, the factor most likely to be responsible being IGFI. ${ }^{52}$ In vivo, the most likely driver for differentiation is contact with particular extracellular matrix components, e.g., collagen IV, ${ }^{53}$ whereas collagen I and III and fibronectin are inhibitory. ${ }^{54,55}$ Most common growth factors (e.g., FGF, EGF, PDGF) appear to either have no clear effect or inhibit differentiation of preadipocytes. ${ }^{56}$

In our model, it is likely that the inflammatory conditions up until week 26 would cause recruitment of macrophages by chemotaxis but prevent their differentiation. Reduction in the inflammatory conditions observed at the 26 week time point would allow spontaneous differentiation, and the start of this process may be occurring as demonstrated by increased expression of vimentin associated with strong ED2 expression. There was not strong Van Geison staining in any of the sponge samples, demonstrating a lack of collagen extracellular matrix expression and further indicative of conditions favorable for adipogenesis to occur.

Surprisingly, little has been reported previously regarding the presence of indigenous leukocytes within natural, white adipose tissue. A recent study ${ }^{57}$ found that they are naturally present, but that their subpopulation composition depended on anatomical location and the presence of obesity. T-lymphocytes expressing $\gamma-\delta$ T-cell receptors are reported to be characteristic of the innate immune system, ${ }^{58,59}$ having functions including modulation of inflammation and macrophage homeostasis ${ }^{60}$ in addition to defense against viral organisms and being adipokine dependent. T-lymphocytes expressing $\alpha-\beta$ receptors, on the other hand, characterized by their involvement in adaptive immunity, appear to be adipokine independent. ${ }^{61}$ The absence of $\gamma-\delta$ T-cells, but the presence of a small number of $\alpha-\beta$ $\mathrm{T}$-cells within the implants, may suggest a response linked to inflammation due to the scaffold rather than generation of neoadipose tissue. Additionally, TGF $\beta$, expressed in small quantities in the scaffolds, has been described as a promoter of preadipocyte proliferation ${ }^{62}$ but an inhibitor of differentiation. ${ }^{63}$ This may explain the continued large number of cells with macrophage-like morphology within the scaffolds and is possibly the period prior to the onset of differentiation of these cells to adipocytes.

It is our continuing belief, therefore, that inflammatory cell infiltration with low levels of activation-related expression (e.g., MHC-II) are likely to be required for the generation of in vivo adipogenesis. The degree of esterification of HYAFF is a key determinant of its in vivo degradation, and a faster rate of adipogenesis is likely to be obtained, based on this hypothesis, by reducing the degree of benzyl esterification. This would make HYAFF a suitable biomaterial for use in the regeneration of soft tissue if re-engineered for faster degradation.

\section{Conclusions}

Fibrous encapsulation of the implanted material was not observed in either sponge type in either of the animal model sites, subcutaneous or intramuscular, suggesting that HYAFF11 had become successfully integrated into the host tissue. While an apparently sustained inflammatory response was observed within both sponge types up to and including 26 weeks, it was relatively benign and nonspecific and was not directed toward 


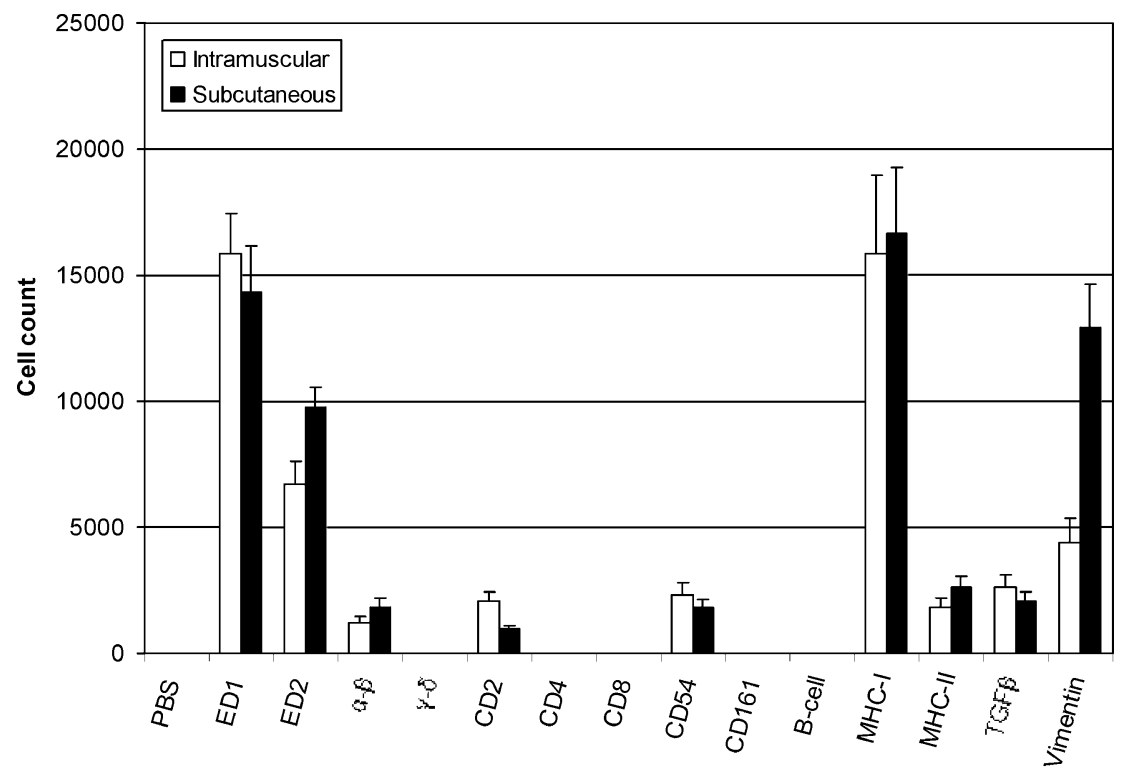

Stain identity

Figure 5. Numbers of different cell types and subpopulations identified by immunohistochemistry surrounding implants of HYAFF11 after implantation for 26 weeks both subcutaneously and intramuscularly in a rat model. Mean $\pm \mathrm{SEM}, n=5$ rats.

(a)

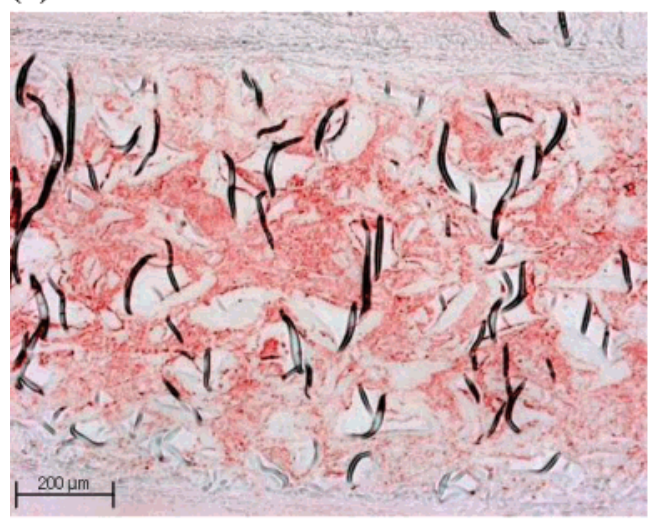

(c)

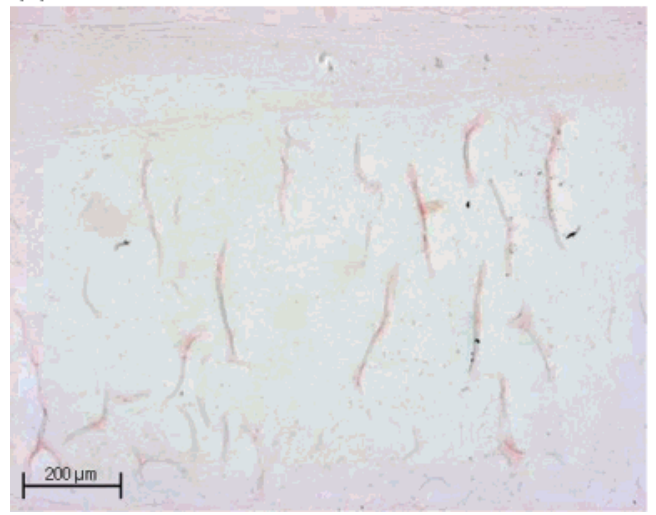

(b)

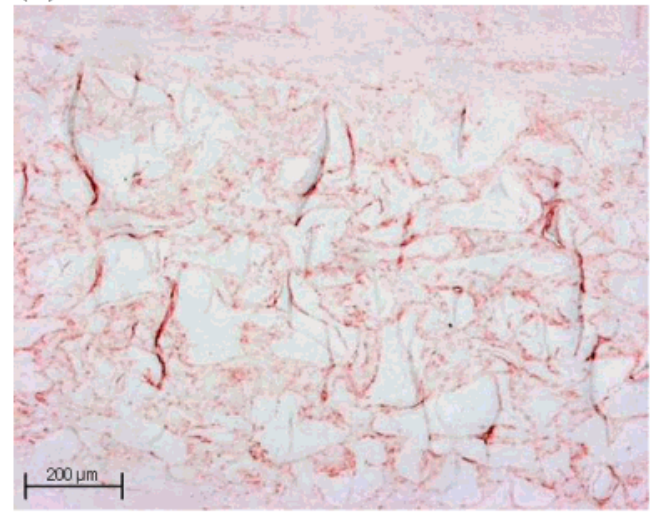

(d)

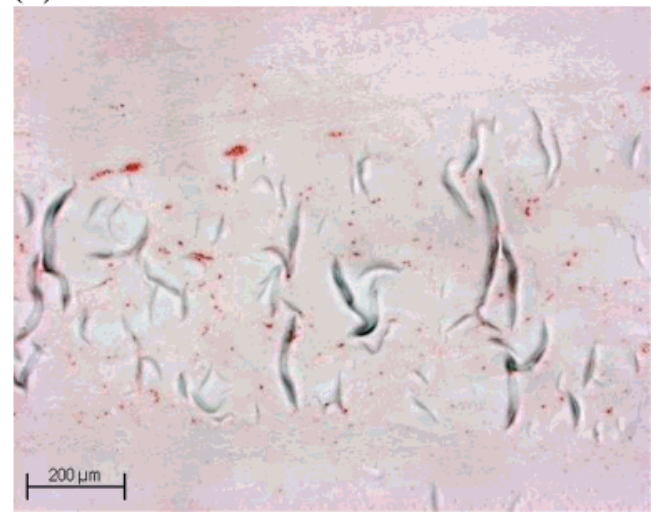

Figure 6. HYAFF11, 26 weeks subcutaneous implantation: (a) monocytes and immature macrophages (ED1); (b) differentiating macrophages (ED2); (c) $\alpha-\beta$ T-cell receptor; (d) TGF $\beta$.

T-lymphocytes or their activation and so could not be regarded as a specific immune response. Induction of neovasculargenesis was observed, and mature adipocytes were observed at the margins of the sponges, and occasionally within their central regions, suggesting HYAFF11 represents an adipocyte-compatible environment. The pattern of vimentin expression and the small levels of TGF $\beta$ expression are consistent with the late onset of differentiation of macrophages into adipocytes, although this could not be confirmed experimentally. It is hypothesized that moderate inflammatory conditions cause the infiltration of macrophages, and a subsequent reduction in inflammatory chemokine secretions allows their spontaneous differentiation, 
due to contact with appropriate extracellular matrix proteins, into adipocytes. It is concluded that hydrophilic coating of HYAFF does not influence the infiltration of cells and that HYAFF11 sponges of either type could be utilized successfully as candidate materials for scaffolds for soft tissue reconstruction, if suitably re-engineered for faster degradation.

Acknowledgment. The authors thank the EPSRC for providing an Advanced Research Fellowship for Nicholas Rhodes. Funding is acknowledged from the European Commission, Project No. GRD1-1999-11159. Parts of the research were performed as part of the Interdisciplinary Research Collaboration in Tissue Engineering for which funds were provided by the BBSRC, MRC, and EPSRC.

\section{References and Notes}

(1) Fokin, A. A.; Robicsek, F. Ann. Thorac. Surg. 2002, 74, 22182225.

(2) Finch, G. D.; Dawe, C. J. J. Pediatr. Orthop. 2003, 23, 99-101.

(3) Sajjadian, A.; Magge, K. T. Aesthetic Surg. J. 2007, 27, 100-104.

(4) Billings, E.; May, J. W. Plast. Reconstr. Surg. 1989, 83, 368-381.

(5) Patrick, C. W. Anat. Rec. 2001, 263, 361-366.

(6) Gomillion, C. T.; Burg. K. J. L. Biomaterials 2006, 27, 6052-6063.

(7) Hemmrich, K.; von Heimburg, D. Expert Rev. Med. Dev. 2006, 3, $635-645$.

(8) Lee, J. A.; Parrett, B. M.; Conejero, J. A.; Laser, J.; Chen, J.; Kogon, A. J.; Nanda, D.; Grant, R. T.; Breitbart, A. S. Ann. Plast. Surg. 2003, 50, 610-617.

(9) Montesano, R.; Kumar, S.; Orci, L.; Pepper, M. S. Lab. Invest. 1996, 75, 249-262.

(10) Culty, M.; Nguyen, H. A.; Underhill, C. B. J. Cell Biol. 1992, 116 , 1055-1062.

(11) Laurent, T. C.; Fraser, J. R. E. FASEB J. 1992, 6, 2397-2404

(12) Toole, B. P. GAGs in Morphogenesis. In Cell Biology of the Extracellular Matrix; Hay, E. D., Ed.; Plenum: New York, 1981; pp 259-294.

(13) Iannace, S.; Ambrosio, L.; Nicolais, L.; Rastrelli, A.; Pastorello, A. J. Mater. Sci.: Mater. Med. 1992, 3, 59-64.

(14) Benedetti, L.; Cortivo, R.; Berti, T.; Berti, A.; Pea, F.; Mazzo, M.; Moras, M.; Abatangelo, G. Biomaterials 1993, 14, 1154-1160.

(15) Cortivo, R.; Brun, P.; Rastrelli, A.; Abatangelo, G. Biomaterials 1991, 12, 727-730.

(16) Hume, L.; Kyyronen, K.; Benedetti, L.; Stella, V.; Topp, E. Abstr. Pap.-Am. Chem. Soc. 1992, 203, 67.

(17) Zacchi, V.; Soranzo, C.; Cortivo, R.; Radice, M.; Brun, P.; Abatangelo, G. J. Biomed. Mater. Res. 1998, 40, 187-194.

(18) Tonello, C.; Zavan, B.; Cortivo, R.; Brun, P.; Panfilo, S.; Abatangelo, G. Biomaterials 2003, 24, 1205-1211.

(19) Aigner, J.; Tegeler, J.; Hutzler, P.; Campoccia, D.; Pavesio, A.; Hammer, C.; Kastenbauer, E.; Naumann, A. J. Biomed. Mater. Res. 1998, 42, 172-181.

(20) Marsano, A.; Wendt, D.; Quinn, T. M.; Sims, T. J.; Farhadi, J.; Jakob, M.; Heberer, M.; Martin, I. Biorheology 2006, 43, 553-560.

(21) Gao, R. Z.; Dennis, J. E.; Solchaga, L. A.; Goldberg, V. M.; Caplan, A. I. Tissue Eng. 2002, 8, 827-837.

(22) Solchaga, L. A.; Temenoff, J. S.; Gao, J. Z.; Mikos, A. G.; Caplan, A. I.; Goldberg, V. M. Osteoarthritis Cartilage 2005, 13, 297-309.

(23) Rhodes, N. P.; Srivastava, J. K.; Smith, R. F.; Longinotti, C. J. Mater. Sci.: Mater. Med. 2004, 15, 391-395.

(24) Cristino, S.; Grassi, F.; Toneguzzi, S.; Piacentini, A.; Grigolo, B.; Santi, S.; Riccio, M.; Tognana, E.; Facchini, A.; Lisignoli, G. J. Biomed. Mater. Res., Part A 2005, 73, 275-283.

(25) Revell, P. A.; Damien, E.; Di Silvio, L.; Gurav, N.; Longinotti, C.; Ambrosio, L. J. Mater. Sci.: Mater. Med. 2007, 18, 303-308.

(26) Pastorino, L.; Soumetz, F. C.; Ruggiero, C. IEE Proc. Nanobiotechnol. 2006, 153, 16-20.

(27) Lepidi, S.; Abatangelo, G.; Vindigni, V.; Deriu, G. P.; Zavan, B.; Tonello, C.; Cortivo, R. FASEB J. [Online] 2006, 20, 103-105. doi: 10.1096/fj.05-4802fje.

(28) Lepidi, S.; Grego, F.; Vindigni, V.; Zavan, B.; Tonello, C.; Deriu, G. P.; Abatangelo, G.; Cortivo, R. Eur. J. Vasc. Endovasc. Surg. 2006, 32, 411-417.

(29) Zavan, B.; Brun, P.; Vindigni, V.; Amadori, A.; Habeler, W.; Pontisso, P.; Montemurro, D.; Abatangelo, G.; Cortivo, R. Biomaterials 2005, 26, 7038-7045.
(30) Halbleib, M.; Skurk, T.; de Luca, C.; von Heimburg, D.; Hauner, H. Biomaterials 2003, 24, 3125-3132.

(31) von Heimburg, D.; Zachariah, S.; Low, A.; Pallua, N. Plast. Reconstr Surg. 2001, 108, 411-420.

(32) Hemmrich, K.; von Heimburg, D.; Rendchen, R.; di Bartolo, C.; Milella, E.; Pallua, N. Biomaterials 2005, 26, 7025-7037.

(33) Patrick, C. W.; Chauvin, P. B.; Hobley, J.; Reece, G. P. Tissue Eng. 1999, 2, 139-151.

(34) Kral, J. G.; Crandall, D. L. Plast. Reconstr. Surg. 1999, 104, 17321738.

(35) Saillan-Barreau, C.; Cousin, B.; André, M.; Villena, P.; Casteilla, L.; Pénicaud, L. Biochem. Biophys. Res. Commun. 2003, 309, 502505.

(36) Planat-Benard, V.; Silvestre, J. S.; Cousin, B.; Andre, M.; Nibbelink, M.; Tamarat, R.; Clergue, M.; Manneville, C.; Saillan-Barreau, C.; Duriez, M.; Tedgui, A.; Levy, B.; Penicaud, L.; Casteilla, L. Circulation 2004, 109, 656-663.

(37) Trayhurn, P.; Wood, I. Br. J. Nutr. 2004, 92, 347-355.

(38) Wu, H. Z, Ghosh, S.; Perrard, X. D.; Feng, L. L.; Garcia, G. E. Perrard, J. L.; Sweeney J. F.; Peterson, L. E.; Chan, L.; Smith, C. W.; Ballantyne, C. M. Circulation 2007, 115, 1029-1038.

(39) Lacasa, D.; Taleb, S.; Keophiphath, M.; Miranville, A.; Clement, K. M. Endocrinology 2007, 148, 868-877.

(40) Kim, C. S.; Kawada, T.; Yoo, H.; Kwon, B. S.; Yu, R. FEBS Lett. 2003, 548, 125-130

(41) Hong, K. M.; Burdick, M. D.; Phillips, R. J.; Heber, D.; Strieter, R. M. FASEB J. 2005, 19, 2029-2031.

(42) Hausman, G. J.; Richardson, R. L. J. Anim. Sci. 2004, 82, 925-934.

(43) Charrière, G.; Cousin, B.; Arnaud, E.; André, M.; Bacou, F.; Pénicaud, L.; Casteilla, L. J. Biol. Chem. 2003, 278, 98509855

(44) Fantuzzi, G. J. Allergy Clin. Immunol. 2005, 115, 911-919.

(45) Ghanim, H.; Aljada, A.; Hofmeyer, D.; Syed, T.; Mohanty, P.; Dandona, P. Circulation 2004, 110, 1564-1571.

(46) Clement, K.; Viguerie, N.; Poitou, C.; Carette, C.; Pelloux, V.; Curat, C. A.; Sicard, A.; Rome, S.; Benis, A.; Zucker, J. D.; Vidal, H.; Laville, M.; Barsh, G. S.; Basdevant, A.; Stich, V.; Cancello, R.; Langin, D. FASEB J. 2004, 18, 1657-1669.

(47) Neels, J. G.; Thinnes, T.; Loskutoff, D. J. FASEB J. 2004, 18, 983985.

(48) Pujol, B. F.; Lucibello, F. C.; Gehling, U. M.; Lindemann, K. Weidner, N.; Zuzarte, M. L.; Adamkiewicz, J.; Elsasser, H. P.; Muller, R.; Havemann, K. Differentiation 2000, 65, 287-300.

(49) Rehman, J.; Li, J. L.; Orschell, C. M.; March, K. L. Circulation 2003 , 107, 1164-1169.

(50) Teichert-Kuliszewska, K.; Hamilton, B. S.; Roncari, D. A.; Kirkland, J. L.; Gillon, W. S.; Deitel, M.; Hollenberg, C. H. Int. J. Obes. 1996 20 (Suppl. 3), S108-S113.

(51) Gregoire, F. M.; Smas, C. M.; Sul, H. S. Physiol. Rev. 1998, 78, $783-809$

(52) Deslex, S.; Negrel, R.; Ailhaud, G. Exp. Cell Res. 1987, 168, 1530.

(53) Ono, M.; Aratani, Y.; Kitagawa, I.; Kitagawa, Y. Exp. Cell Res. 1990, 187, 309-314

(54) Bortell, R.; Owen, T. A.; Ignotz, R.; Stein, G. S.; Stein, J. L. J. Cell. Biochem. 1994, 54, 256-263.

(55) Weiner, F. R.; Shah, A.; Smith, P. J.; Rubin, C. S.; Zern, M. A Biochemistry 1989, 28, 4094-4099.

(56) Hauner, H.; Rohrig, K.; Petruschke, T. Eur. J. Clin. Invest. 1995 25, 90-96.

(57) Caspar-Bauguil, S.; Cousin, B.; Galinier, A.; Segafredo, C.; Nibbelink, M.; André, M.; Casteilla, L.; Pénicaud, L. FEBS Lett. 2005, 579 , 3487-3492.

(58) Kaufmann, S. H. E. Proc. Natl. Acad. Sci. U.S.A. 1996, 93, 22722279.

(59) Jameson, J. M.; Sharp, L. L.; Witherden, D. A.; Havran, W. L. Front. Biosci. 2004, 9, 2640-2651.

(60) Dalton, J. E.; Pearson, J.; Scott, P.; Carding, S. R. J. Immunol. 2003, $171,6488-6494$

(61) Caspar-Bauguil, S.; Cousin, B.; André, M.; Nibbelink, M.; Galinier A.; Periquet, B.; Casteilla, L.; Pénicaud, L. Exp. Cell Res. 2006, 12, 2195-2202.

(62) Richardson, R. L.; Hausman, G. J.; Gaskins, H. R. Acta Anat. 1992 145, 321-326.

(63) Shin, S. M.; Kim, K.-Y.; Kim, J. K.; Yoon, S. R.; Choi, I.; Yang, Y. FEBS Lett. 2003, 543, 25-30.

BM070368P 